\title{
Comparison of keratometry readings and corneal astigmatism obtained with Verion image-guided system, Pentacam, and intraocular lens Master in patients undergoing toric intraocular lens implantation
} Sherif Emerah ${ }^{\mathrm{a}, \mathrm{b}}$, Hani Labib ${ }^{\mathrm{a}}$, Tarek Saleh ${ }^{\mathrm{a}}$

aDepartment of Ophthalmology, Research Institute of Ophthalmology, Giza, Egypt,

${ }^{b}$ Magrabi Eye Hospital, Dubai, UAE

Correspondence to Sherif Emerah, MD, FRCS, ALRazi Building \#64, Block C, 1st floor, Dubai Health Care City, Dubai, UAE. Tel: +971566 538 724; fax: +971 44211322; e-mails: sherifemera@yahoo.com

Published: 2020

The Egyptian Journal of Cataract and Refractive Surgery 2020

\begin{abstract}
Purpose
Tocompare the keratometry $(\mathrm{K})$ values and corneal astigmatism obtained using the Verion image-guided system, Pentacam, and intraocular lens (IOL) Master. Patients and methods

This retrospective study evaluated 96 eyes of 58 patients scheduled for toric IOL implantation.

Results

The study included 96 eyes of 58 patients with cataract, among those 34 (58.6\%) were men and 24 (41.4\%) were women. Age of the patients ranged from 35 to 82 years, with a mean of $54.7 .50 \pm 16.1$ years. Double data entry on SPSS program, version 23 was done. A $P$ value of less than 0.05 was considered statistically significant. Mean flat $\mathrm{K}$ (Kf) was $43.3 \pm 1.8,43.3 \pm 1.7$, and $43.2 \pm 1.6$ in Verion, Pentacam, and IOL Master, respectively. Mean steep K (Ks) was $45.3 \pm 1.8,41.1$ \pm 1.7 , and $45.2 \pm 1.6$ in Verion, Pentacam, and IOL Master, respectively. Mean average $\mathrm{K}$ was $43.3 \pm 1.7,44.2 \pm 1.6$, and $44.2 \pm 1.56$ in Verion, Pentacam, and IOL Master, respectively. Mean astigmatism was $1.8 \pm 0.9,2.0 \pm 1.0$, and $1.98 \pm 1.0$ in Verion, Pentacam, and IOL Master, respectively. There was no statistically significant difference among the three devices.

Conclusion

The $\mathrm{K}$ values, power of corneal astigmatism, have no significant difference, and there is a good agreement among the Verion, IOL Master, and Pentacam. Verion image-guided system is a reliable system and can be interchangeably used with other currently used devices.
\end{abstract}

\section{Keywords:}

corneal astigmatism, corneal curvature, image-guided system, toric intraocular lens

2020 the Egyptian journal of Cataract and refractive surgery

1687_6997

\section{Introduction}

Cornea is one of the main refractive surfaces of the eye, making up $\sim 70 \%$ of the refractive power of the human eye. Keratometry is a method to measure corneal surface powers. To calculate intraocular lens (IOL) refractive power, corneal curvature measurement plays a key role [1].

Toric IOL implantation is an effective and safe method in correcting astigmatism. Accurate calculation of IOL power is a crucial step toward a satisfactory refractive outcome for patients. For both toric and nontoric lens calculation, precise and reliable keratometry has to be performed [2].

Accurate keratometry values are also used as a part of surgical planning for corneal incision site, astigmatic keratotomy, the management of surgery-induced astigmatism, and correcting postoperative residual astigmatism [3].
The Verion image-guided system is a new surgicalassisted platform. Real-time visual image marking under operating microscope can facilitate accurate placement of toric IOL during surgery [4]. The IOL Master is considered to be the gold standard for measuring $\mathrm{K}$ readings and preoperative IOL power calculation. Its refractive results were reviewed in multiple studies, showing it provides a reliable clinical outcome [5-7]. Pentacam is more commonly used for topographic purposes, such as refractive surgery and keratoconus screenings $[8,9]$.

The main aim of this study was to assess data accuracy of the Verion Reference Unit and compare them with those of the IOL Master and Pentacam devices. We

This is an open access journal, and articles are distributed under the terms of the Creative Commons Attribution-NonCommercial-ShareAlike 4.0 License, which allows others to remix, tweak, and build upon the work non-commercially, as long as appropriate credit is given and the new creations are licensed under the identical terms. 
compared the following data: flat $\mathrm{K}(\mathrm{Kf})$, steep $\mathrm{K}(\mathrm{Ks})$, and average $\mathrm{K}$ ( $\mathrm{K}$ average) readings and corneal astigmatism.

\section{Patients and methods}

Patients having routine cataract surgery and toric IOL implantation were included in this retrospective study. A total of 96 eyes of 58 patients were included in the study. All patients received a preoperative comprehensive examination including uncorrected distance visual acuity, slit-lamp bio-microscopy, noncontact tonometry, and fundus examination after pupil dilation.

For IOL calculations, all patients were subjected to keratometric assessment using the Pentacam, IOL Master, and Verion image-guided system. Three consecutive readings were taken by each device, and average readings were recorded. Steep, flat, and mean keratometric readings and corneal astigmatism were compared by the three systems. All participants signed an informed consent form in accordance with the tenets of the Declaration of Helsinki.

The Verion Reference Unit (Alcon, Fort Worth, Texas, USA) obtains the curvature and power of the patient's cornea by calculation of the position and shape of 15 projected light reflections created by three infrared and 12 white light-emitting diodes (LEDs). The measurement procedure consists of two steps. In the first step, the near-infrared reflexes on the cornea are used to determine the corneal spherical power on a diameter of $0.8-1.2 \mathrm{~mm}$. In the second step, central $2.8 \mathrm{~mm}$ of the cornea was used to produce the still image and determine corneal cylinder and astigmatism axis. The total measurement time is $\sim 20$ s. Preoperative corneal curvature data can be integrated with anterior segment imaging for intraoperative image registration. Verion system corrects automatically the cyclotorsion by recognizing scleral blood vessels and iris features. It assists the surgeon in adjusting the IOL centration and performing accurate IOL alignment in toric IOL implantation.

Pentacam (OCULUS Optikgeräte GmbH, Wetzlar, Germany) uses a rotational Scheimpflug camera that measures, among other parameters, the anterior and posterior corneal radii. As the Scheimpflug camera rotates, it records 25 separate images of an eye to provide a composite image, which is focused across the entire plane of the anterior segment. It uses an LED (ultraviolet-free blue light, $475 \mathrm{~nm}$ ) for illumination.
IOL Master (Carl Zeiss Meditec AG, Jena, Germany) is noncontact biometry that can determine the axial length of the eye by partial coherence interferometry. It uses automated keratometry to measure the anterior corneal curvature. Six LEDs are projected onto the cornea in a hexagonal pattern within a $2.3-\mathrm{mm}$ diameter. The separation of the opposite pairs of lights is measured objectively by the instrument's software. In the case of an astigmatic cornea, the curvature is calculated from three, fixed-position meridians. It also uses 1 LED (white light, $590 \mathrm{~nm}$ ) for WTW measurements.

\section{Statistical analysis}

Data were revised for completeness and consistency. Double data entry on SPSS program, version 23 was done (IBM, NY, USA). Quantitative data were summarized by mean and $\mathrm{SD}$, whereas qualitative data were summarized by frequencies and percentages. One-way analysis of variance test was used in the analysis of the results. A $P$ value of less than 0.05 was considered statistically significant.

\section{Results}

The study included 96 eyes of 58 patients with cataract, comprising 34 (58.6\%) men and 24 (41.4\%) women. Age of the patients ranged from 35 to 82 years, with a mean of $54.7 .50 \pm 16.1$ years.

\section{Flat keratometry}

Mean Kf was 43.3 \pm 1.8 D (range, 39.348 .5 D), 43.3 $\pm 1.7 \mathrm{D}$ (range, 39.3-48.1 D), and 43.2 $\pm 1.6 \mathrm{D}$ (range, 38.6-47.0 D) in Verion, Pentacam, and IOL Master, respectively. There was no statistically significant difference in the mean $\mathrm{Kf}$ among the three devices $(P=0.9)$ (Table 1 and Fig. 1).

\section{Steep keratometry}

Mean Ks was 45.3 \pm 1.8 D (range, 41.4-51.1 D), 41.1 $\pm 1.7 \mathrm{D}$ (range, 40.5-50.1 D), and 45.2 $\pm 1.6 \mathrm{D}$ (range, 41.0-48.9 D) in Verion, Pentacam, and IOL Master, respectively. There was no statistically significant

Table 1 Mean Values of $\mathrm{Kf}, \mathrm{Ks}, \mathrm{K}$ average and corneal astigmatism measured by the 3 devices

\begin{tabular}{lcccc}
\hline$N=96$ & $\begin{array}{c}\text { Mean } \\
\mathrm{Kf}\end{array}$ & $\begin{array}{c}\text { Mean } \\
\mathrm{Ks}\end{array}$ & $\begin{array}{c}\text { Mean } \\
\text { average }\end{array}$ & $\begin{array}{c}\text { Mean } \\
\text { astigmatism }\end{array}$ \\
\hline Verion & 43.3 & 45.3 & $44.3 \pm 1.7$ & $2.03 \pm 1.0$ \\
& \pm 1.8 & \pm 1.8 & & \\
Pentacam & 43.3 & 45.1 & $44.2 \pm 1.6$ & $1.85 \pm 0.9$ \\
IOL & \pm 1.7 & \pm 1.7 & & \\
Master & 43.2 & 45.2 & $44.2 \pm 1.5$ & $1.98 \pm 1.0$ \\
\hline
\end{tabular}

IOL, intraocular lens; Kf, flat keratometry; Ks, steep keratometry. 
Figure 1

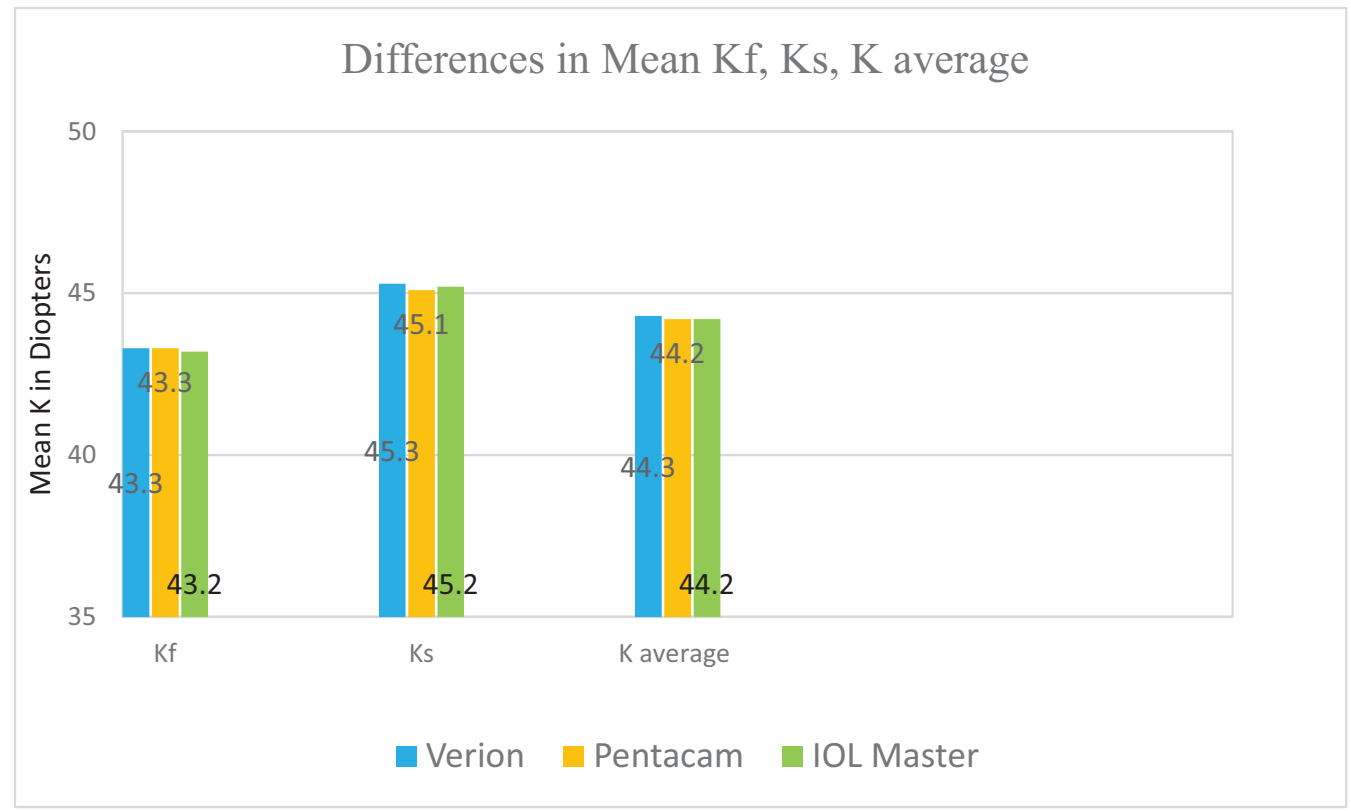

Mean Values of Kf, Ks and $\mathrm{K}$ average measured by the 3 devices.

Figure 2

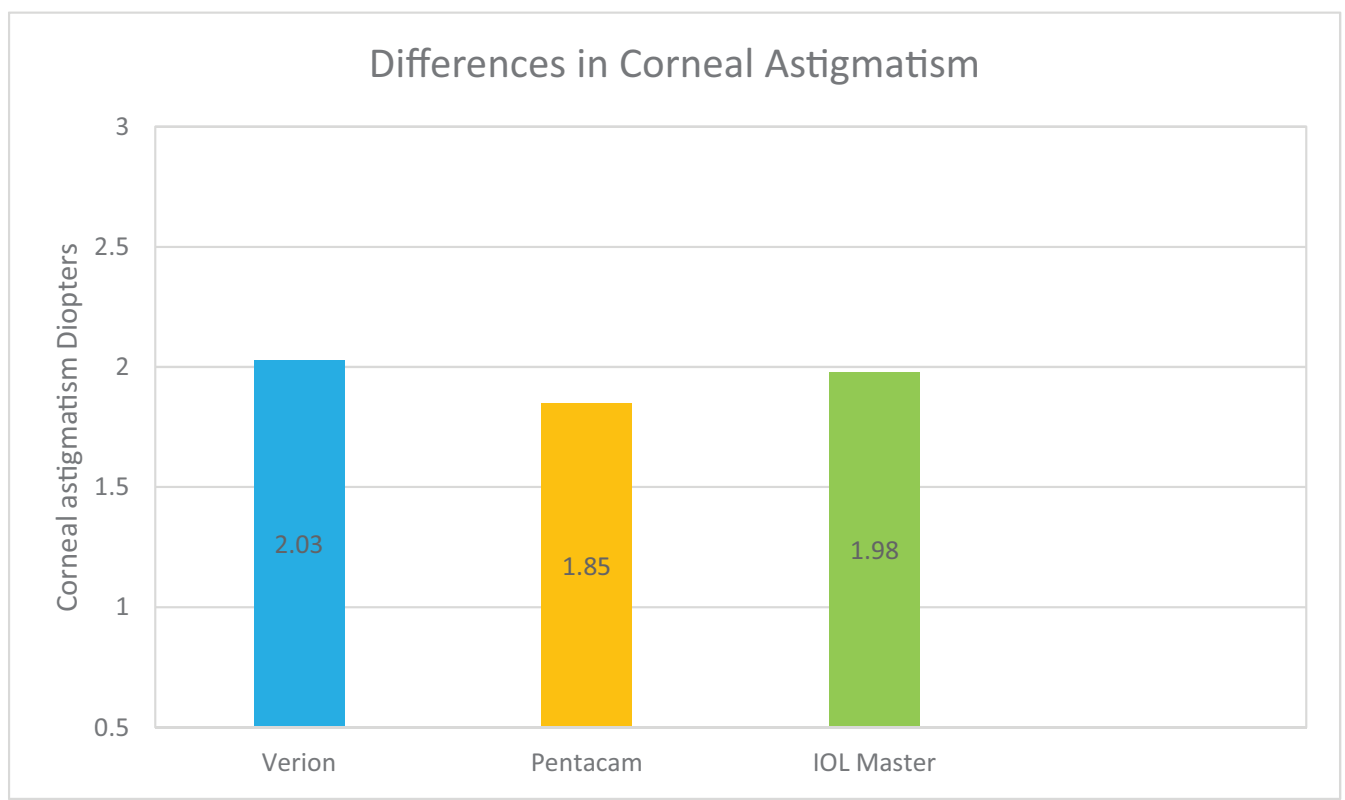

Mean value of corneal astigmatism measured by the 3 devices.

difference in the mean Ks among the three devices $(P=0.6)$ (Table 1 and Fig. 1).

\section{Average keratometry}

Mean average $\mathrm{K}$ was $43.3 \pm 1.7 \mathrm{D}$ (range, 40.5-49.8 D), 44.2 $\pm 1.6 \mathrm{D}$ (range, 40.0-49.1 D), and 44.2 \pm 1.5 D (range, 40.4-47.3 D) in Version, Pentacam, and IOL Master, respectively. There were no statistically significant differences in the mean average $\mathrm{K}$ among the three devices $(P=0.8)$ (Table 1 and Fig. 1).

\section{Corneal astigmatism}

Mean corneal astigmatism was $1.8 \pm 0.9 \mathrm{D}$ (range, 0.4-4.7 D), 2.0 $1.0 \mathrm{D}$ (range, 0.48-5.9 D), and 1.98 $\pm 1.0 \mathrm{D}$ (range, 0.4-5.4 D) in Verion, Pentacam, and IOL Master, respectively. There was no statistically significant difference in the mean corneal 
astigmatism among the three devices $(P=0.4)$ (Table 1 and Fig. 2).

Results showed that the difference was not significant, and the three devices can be used interchangeably.

\section{Discussion}

Keratometry has its contribution in evaluation of anterior segment diseases as well as IOL power calculation before cataract surgery. The present study compares keratometric readings and corneal astigmatism measured by Verion image-guided system, Pentacam, and IOL Master.

Our results showed that there were no statistically significant differences in $\mathrm{K}$ steep, $\mathrm{K}$ flat, average $\mathrm{K}$, and corneal astigmatism among the three devices. Our results are consistent with other studies.

Nemeth et al. [10] did not find any significant difference between the Verion system and the IOL Master regarding the $\mathrm{K}$ values, power, and axis of astigmatism. Lauschke et al. [11] found no statistically significant difference between Verion values and those obtained by IOL Master and Pentacam in relation to mean keratometry, corneal astigmatism, steep meridian, and vector analyses. Their results showed narrow limits of agreement for keratometry and astigmatism and wider agreement for steep meridian.

Habib et al. [12] compared flat K, steep K, and astigmatism by Verion, Pentacam, and Gallili. Their results showed no significant difference in dioptric power of astigmatism between Verion and Pentacam. Correlation analysis showed agreement between individual variables measured by the three devices. They concluded that devices can be used interchangeably. $\mathrm{Wu}$ et al. [13] found a good agreement among the Verion, IOL Master, and Pentacam. They did not find significant difference in keratometric power, magnitude, and steep axis of astigmatism. They concluded that Verion imageguided system is a reliable system for the measurement of keratometry values and astigmatism.

On other studies, significant flatter keratometric value was found with the Verion than the Pentacam and IOL Master [14]. There was no significant difference between the Verion system and the IOL Master regarding the $K$ values, power, and axis of astigmatism. Additionally, the
IOL Master measured the biggest astigmatism power, whereas the image-guided device measured the second highest power among six keratometry devices. Moreover, the highest axis of astigmatism was obtained with the Verion. In the same study, Verion appeared to have significantly flatter keratometric values than the Pentacam [15]. The same results were reported by Thomas et al. [16]. A probable explanation for these results is the difference in measurement methods. Verion measures the central $2.8 \mathrm{~mm}$ of the cornea, whereas the IOL Master uses six light reflections on the central $2.5 \mathrm{~mm}$. Owing to the fact that cornea is steeper in the center than in the periphery, more central measurements can produce steeper keratometric readings [17].

On a different note, Asena et al. [18] found that keratometric values obtained by the Verion system were significantly higher than the values obtained by the IOL Master. The mean difference was quite small $(<0.20 \mathrm{D})$. Therefore, it was not expected to have a substantial clinical effect. In the same study, a difference of more than $20^{\circ}$ has been observed in the axis of astigmatism between the measurements obtained using the Verion and IOL Master in 21\% of cases.

\section{Conclusion}

Our study has confirmed the previous results showing that Verion, Pentacam, and IOL Master can be interchangeably used in different clinical settings and requirements.

\section{Financial support and sponsorship}

Nil.

\section{Conflicts of interest}

There are no conflicts of interest.

\section{References}

1 Yuan X, Song H, Peng G, Hua X, Tang X. Prevalence of corneal astigmatism in patients before cataract surgery in Northern China. $J$ Ophthalmol 2014; 2014:536412.

2 Viestenz A, Seitz B, Langenbucher A. Evaluating the eye's rotational stability during standard photography: effect on determining the axial orientation of toric intraocular lenses. J Cataract Refract Surg 2005; 31:557-561.

3 Visser N, Bauer NJ, Nuijts RM. Toric intraocular lenses: historical overview, patient selection, IOL calculation, surgical techniques, clinical outcomes, and complications. J Cataract Refract Surg 2013; 39:624-637.

4 Reggiani-Mello G, Krueger RR. Comparison of commercially available femtosecond lasers in refractive surgery. Expert Rev Ophthalmol 2011; 6:55-65.

5 Eleftheriadis H. IOL Master biometry: refractive results of 100 consecutive cases. Br J Ophthalmol 2003; 87:960-963. 
6 Dulku S, Smith HB, Antcliff RJ. Keratometry obtained by corneal mapping versus the IOL Master in the prediction of postoperative refraction in routine cataract surgery. Clin Exp Ophthalmol 2013; 41:12-18.

7 Haigis W, Lege B, Miller N, Schneider B. Comparison of immersion ultrasound biometry and partial coherence interferometry for intraocular lens calculation according to Haigis. Graefes Arch Clin Exp Ophthalmol 2000; 238:765-773

8 Hashemi H, Asgari S, Miraftab M, Emamian MH, Shariati M, Fotouhi A. Agreement study of keratometric values measured by Biograph/LENSTAR, auto-kerato-refractometer and Pentacam: decision for IOL calculation. Clin Exp Optom 2014; 97:450-455.

9 McAlinden C, Khadka J, Pesudovs K. A comprehensive evaluation of the precision (repeatability and reproducibility) of the Oculus Pentacam HR. Invest Ophthalmol Vis Sci 2011; 52:7731-7737.

10 Nemeth G, Szalai E, Hassan Z, Lipecz A, Berta A, Modis L Jr. Repeatability data and agreement of keratometry with the VERION system compared to the IOL Master. J Refract Surg 2015; 31:333-337.

11 Lauschke JL, Lawless M, Sutton G, Roberts TV, Hodge C. Assessment of corneal curvature using verion optical imaging system: a comparative study. Clin Exp Ophthalmol 2016; 44:369-376.

12 Habib A, Khan MS, Ishaq M, Yaqub MA. Agreement between Keratometric readings by VERION image guided System, Galilei G4 and Pentacam. Pak J Med Sci 2018; 34:740-743.
$13 \mathrm{Wu}$ J, Gao P, Fan JW, Li TT, Liu F. Comparison of keratometric measurements obtained by the Verion image guided system with the $\mathrm{IOL}$ Master and the Pentacam before cataract extraction surgery. Zhonghua Yan Ke Za Zhi 2020; 56:47-52.

14 Mueller A, Thomas BC, Auffarth GU, Holzer MP. Comparison of a new image-guided system versus partial coherence interferometry, Scheimpflug imaging, and optical low-coherence reflectometry devices: Keratometry and repeatability. J Cataract Refract Surg 2016; 42:672-678.

15 Schultz $M$, Oberheide $U$, Kermani O. Comparability of an imageguided system with other instruments in measuring corneal keratometry and astigmatism. J Cataract Refract Surg 2016; 42:904-912.

16 Thomas BC, Mueller A, Auffarth GU, Holzer MP. Influence on intraocular lens power calculation of corneal radii measurement using an imageguided system. J Cataract Refract Surg 2016; 42:1588-1594.

17 Shirayama M, Wang L, Weikert MP, Koch DD. Comparison of corneal powers obtained from 4 different devices. Am J Ophthalmol 2009; 148:528-535.

18 Asena L, Gu?ngo?r SG, Akman A. Comparison of keratometric measurements obtained by the Verion Image Guided System with optical biometry and auto-keratorefractometer. Int Ophthalmol 2017; 37:391-399. 